\title{
Facile Preparation of a New BINAP-based Building Block, 5,5'-diiodo-BINAP, and its Synthetic
}

\section{Application}

\author{
Toyoshi Shimada, ${ }^{* * *}$ Masahiko Suda, ${ }^{\S}$ Toyohiro Nagano, ${ }^{*}$ and Kiyomi Kakiuchi ${ }^{\S}$ \\ "Department of Chemical Engineering, Nara National College of Technology, 22 Yata-cho, \\ Yamatokoriyama, Nara 639-1080, Japan and ${ }^{\S}$ Graduate School of Materials Science, Nara Institute of \\ Science and Technology (NAIST), 8916-5, Takayama, Ikoma, Nara 630-0192, Japan.
}

Supporting Informations

\section{Table of Contents}

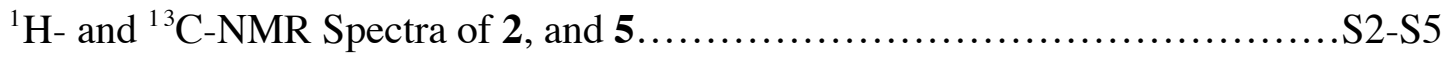

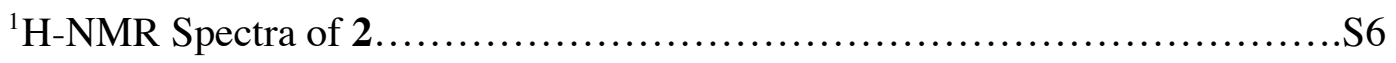




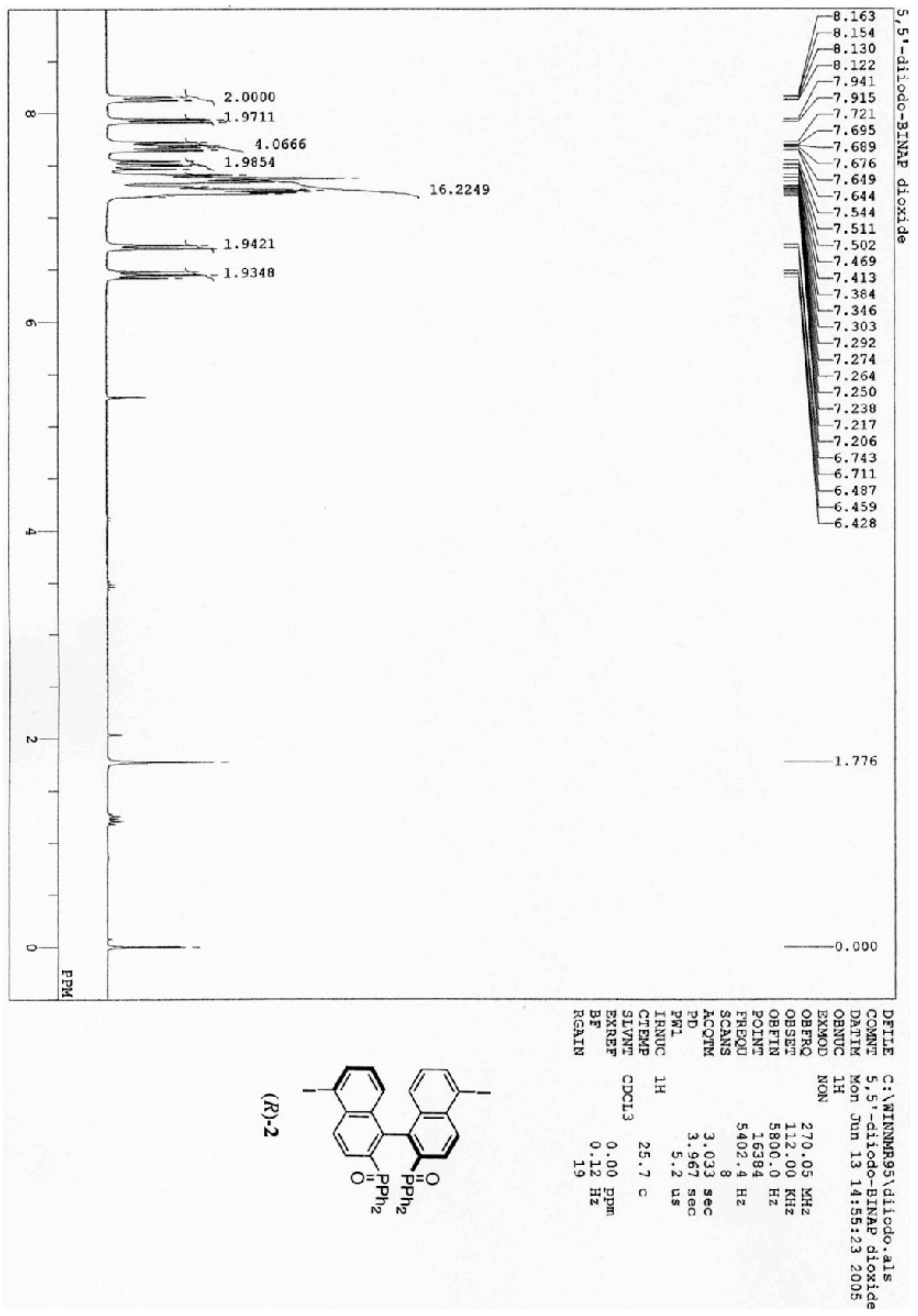




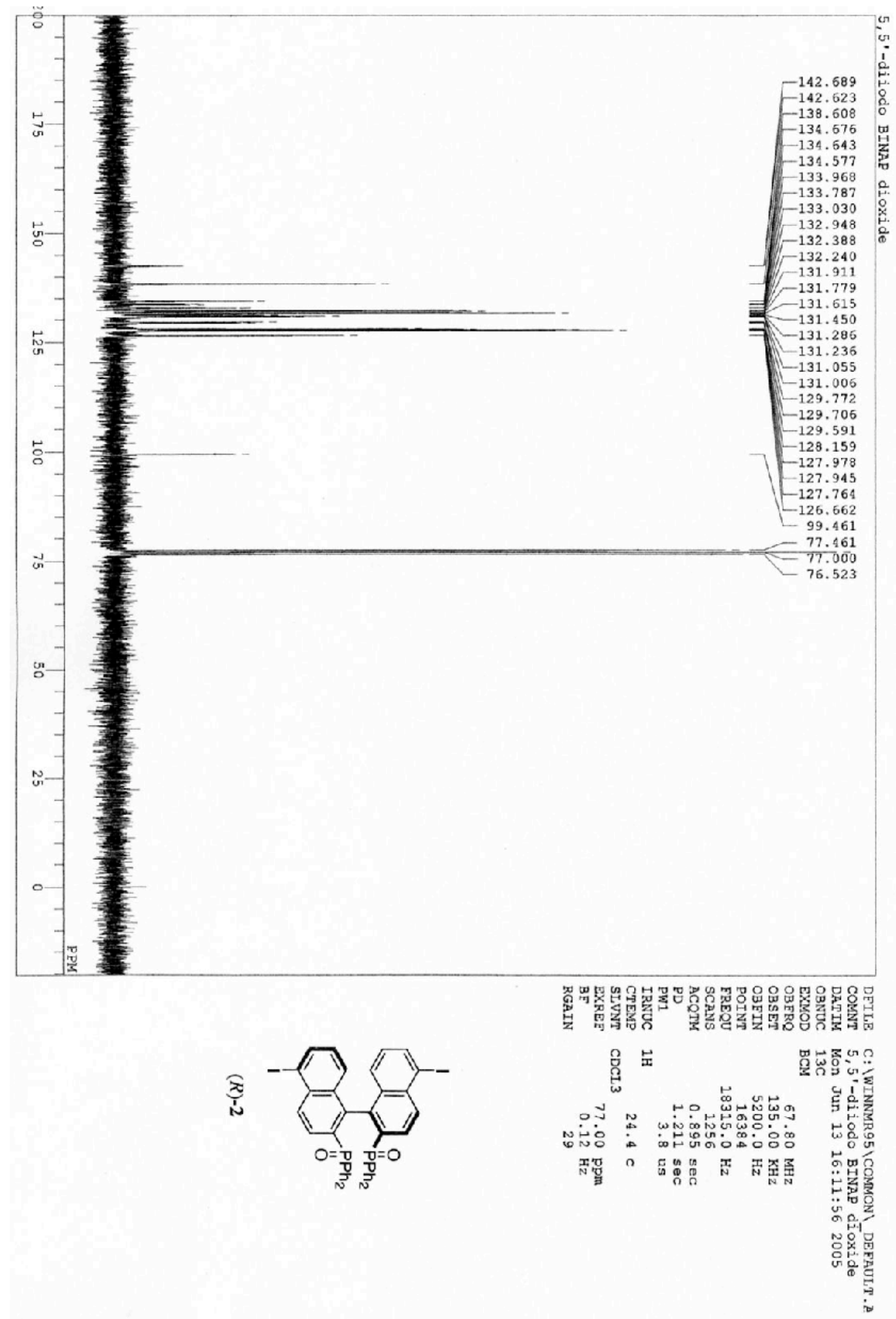




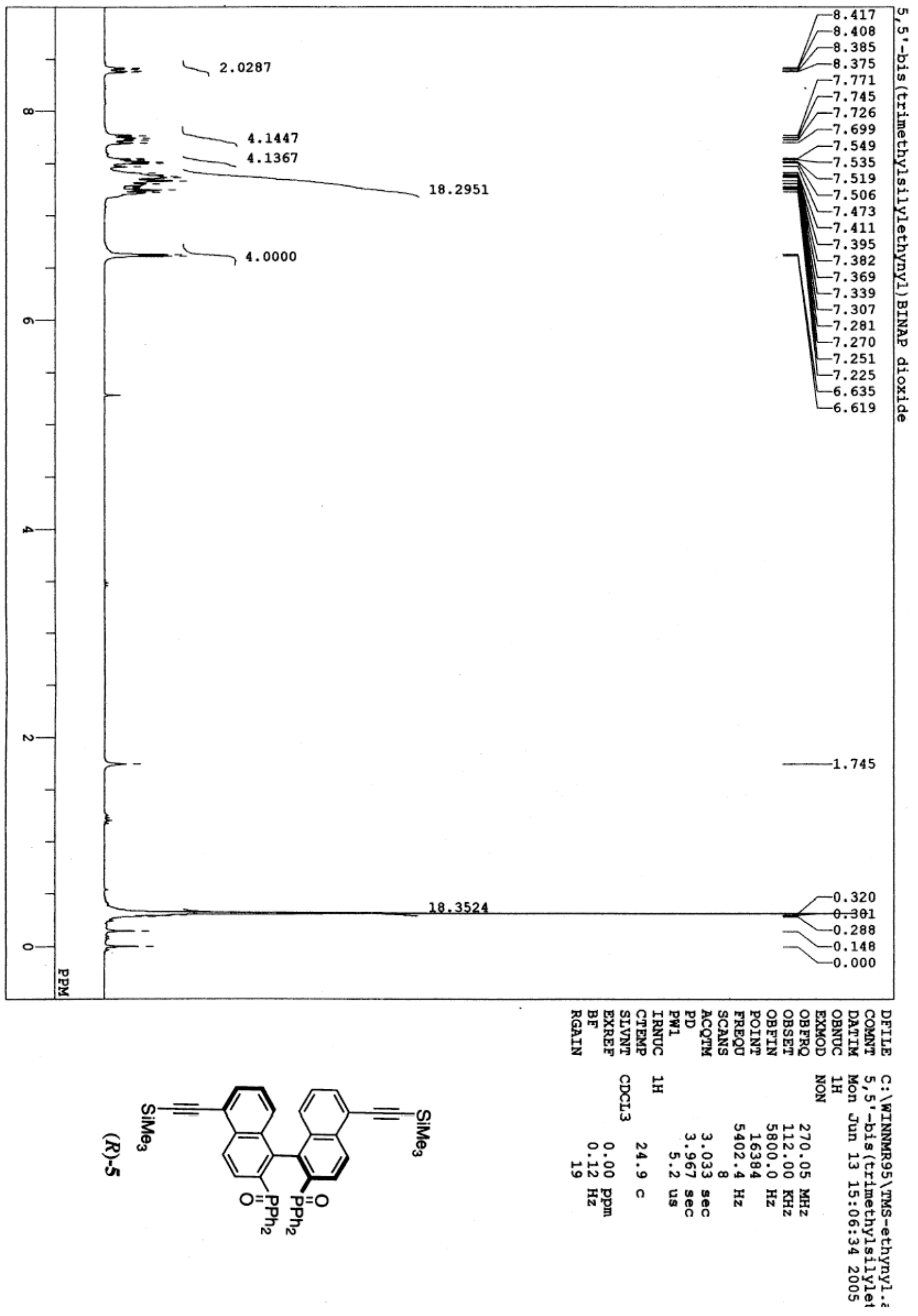




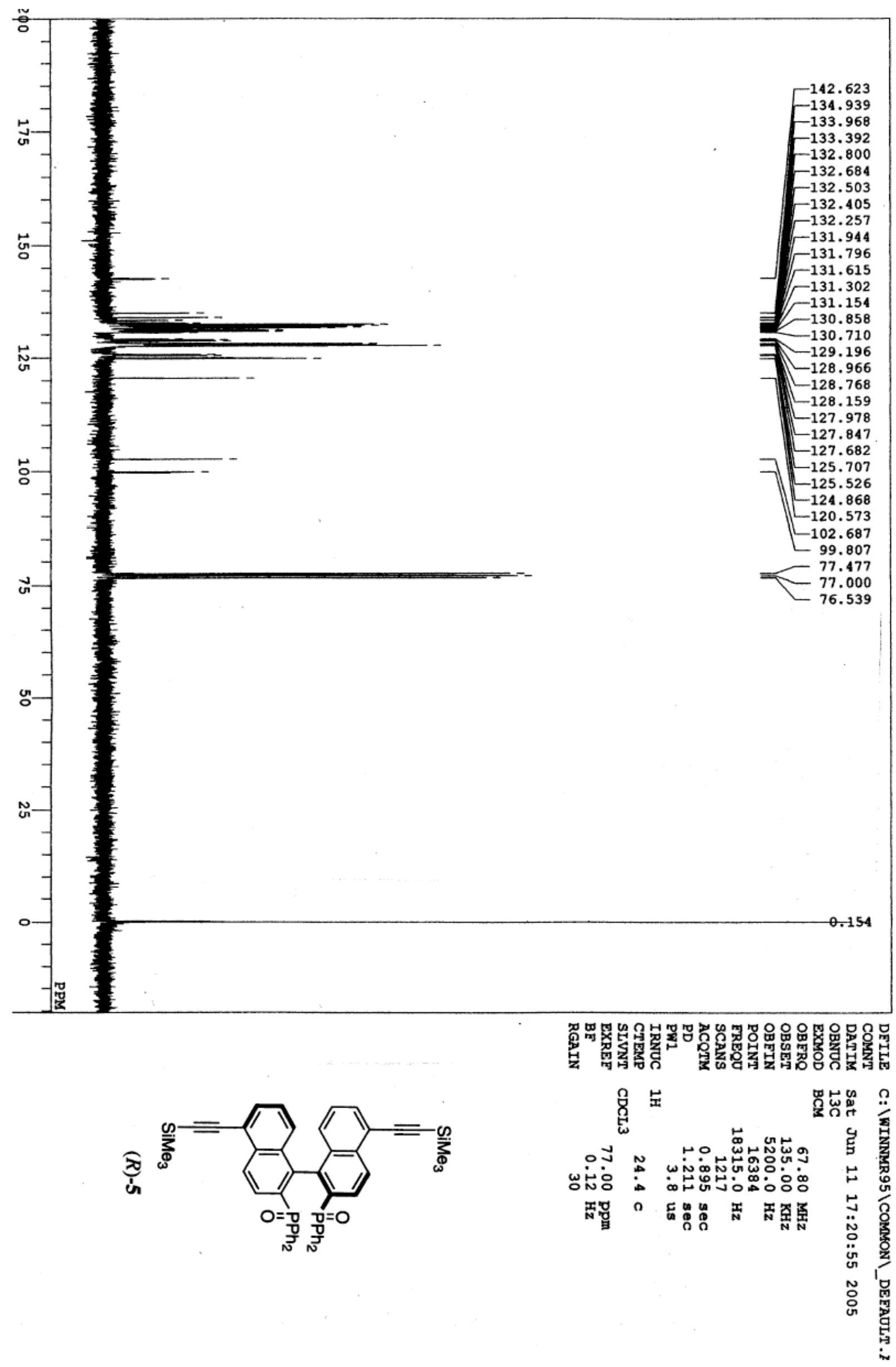




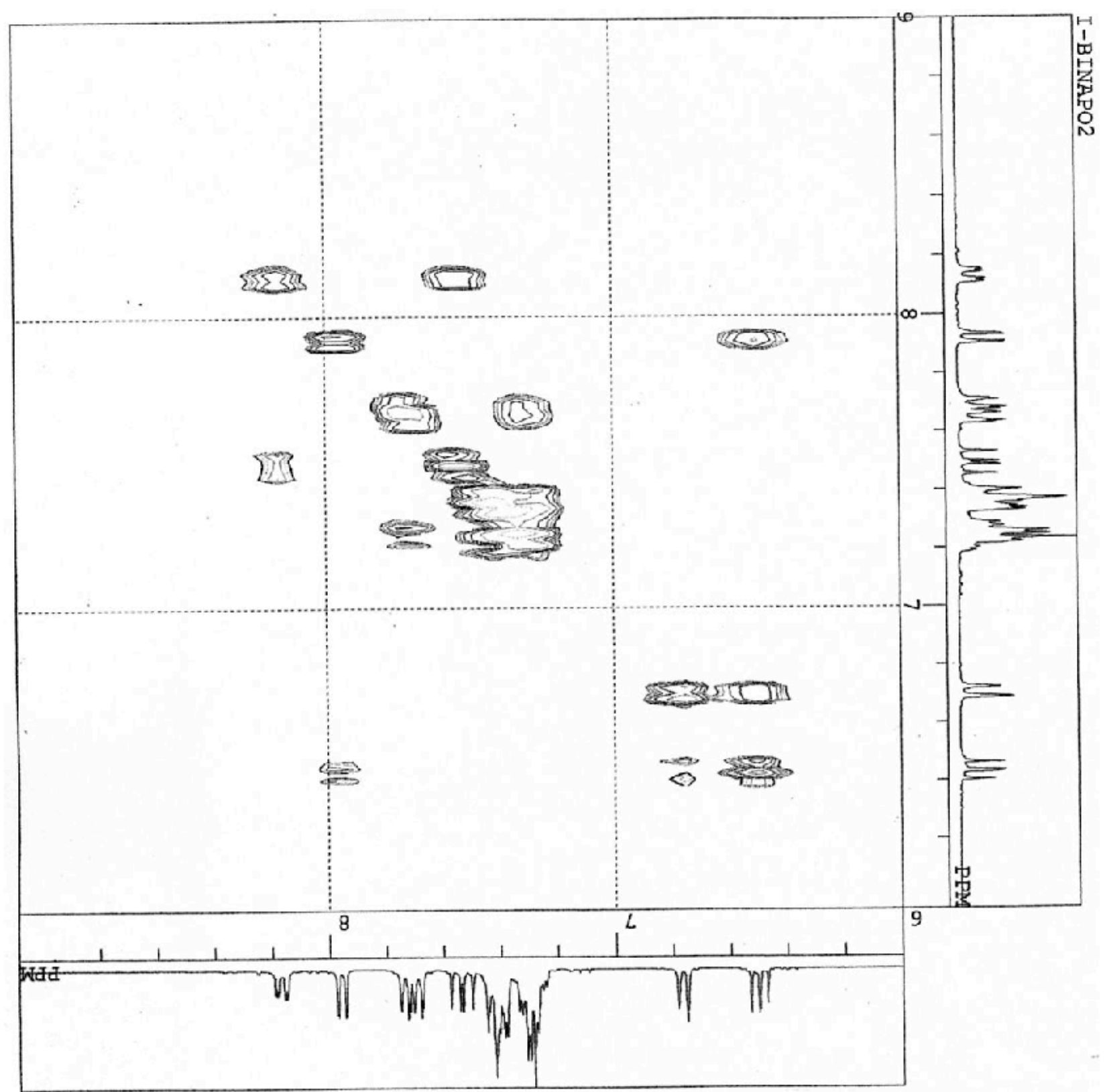

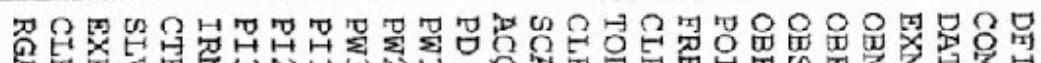

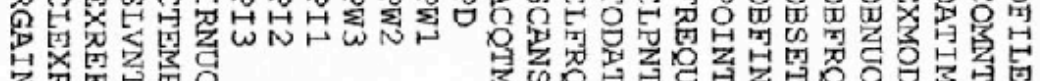

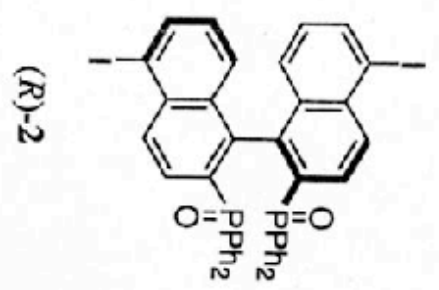

$$
\text { 呑出 }
$$

○ $N$ n

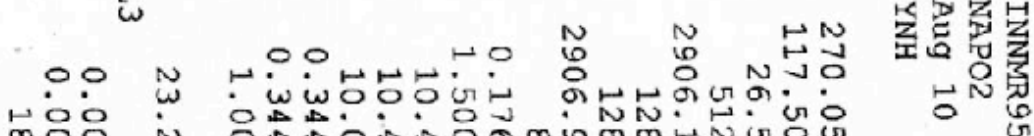

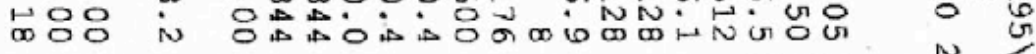

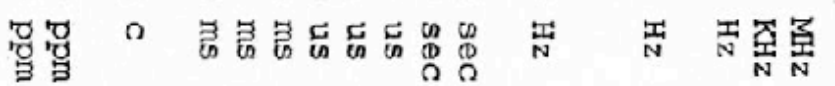

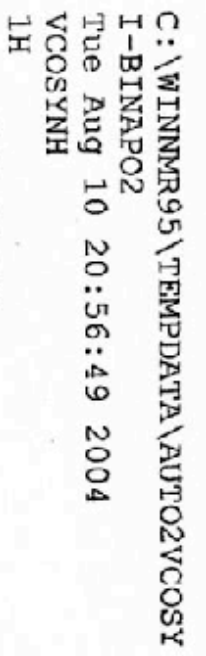

